IP Periodica Polytechnica

Mechanical Engineering

62(3), pp. 218-225, 2018

https://doi.org/10.3311/PPme.12041

Creative Commons Attribution (i)

RESEARCH ARTICLE

\section{Optimization of Safety Factor by Genetic Algorithm of Circular Notched Carbon / Epoxy Laminate at Low Velocity Impact}

\author{
Djilali Beida Maamar ${ }^{1}$, Ramdane Zenasni ${ }^{2}$
}

Received 14 February 2018; accepted after revision 12 April 2018

\begin{abstract}
This work deals with the application of the genetic algorithm to the determination of optimal safety factor of layered structure subjected to low velocity impact damage. These genetic algorithms are optimization algorithms based on the techniques derived from genetics and the natural evolution; crossovers, mutations, selection. The numerical modeling was carried out by the finite element software LS dyna which is coupled to the optimization program Ls-optui. The aim of this work is to minimize the safety factor based on the Tsai-Wu criterion for laminate.

The optimization is held by evaluating the maximal energy that can undergo the material for a minimum safety factor. In this case a composite laminate of stacking [0/30/45/60/90/45] with a circular notch drilled at defined location, then a laminate was targeted at the center by four impactors (cylinder, hemispherical, ball and truncated cone). The optimization was held in two phases; first without taking account the function of delamination and in the second phase with the function of delamination.
\end{abstract}

\section{Keywords}

laminate, low velocity, genetic algorithm, delamination, safety factor, Mat059, Mat020

\footnotetext{
${ }^{1}$ Department of Mechanics, Laboratory LMPC,

Faculty of Science and Engineering,

University Center of Relizane,

48000 Relizane, Algeria

${ }^{2}$ Department of Mechanics, Laboratory LMPC,

Faculty of Science and Engineering,

Mostaganem University,

27000 Mostaganem, Algeria

${ }^{\text {*}}$ Corresponding author, e-mail: zramdane@netcourrier.com
}

\section{Introduction}

The fibrous composites are being increasingly used in load bearing structures due to number of advantages over conventional materials: high specific strength and stiffness, good fatigue performance and corrosion resistance. A serious obstacle to more widespread use is their sensitivity to impact and static loads in the thickness direction. As composites have demonstrated to be very venerable to out of plane impact, which cause barely visible impact damage (BVID) reportedly contributes up to $60 \%$ loss in structures' compressive strength and major reason of catastrophic failures. The energy absorbed during impact is mainly dissipated by a combination of matrix damage, fibre fracture and fibre-matrix de-bonding, which leads to significant reductions in the load carrying capabilities. In ballistic impacts the damage is localized and clearly visible by external inspection, while low velocity impact involves long contact time between impactor and target, which produces global structure deformation with undetected internal damage at points far from the contact region. For such reasons the low velocity impact are often simulated by simple static indentation-flexure tests, neglecting the influence of dynamic effects. It is also suggested the complete model to take into account the full dynamic behavior of the laminates. Composite design optimization typically consists of identifying the optimal configuration that would achieve the required strength with minimum over heads. De Almeida [1] worked on maximizing the buckling load of a symmetric and balanced laminated plate. Performance and sensitivity to the parameters harmony memory size (HMS), harmony memory consideration rate (HMCR) and pitch adjusting rate (PAR) are determined based on the algorithm apparent reliability.

Shahraki and Noorossama [2], presented an improved general methodology including four stages to design robust and reliable products under uncertainties. They consider reliability and robustness simultaneously to propose the new formulation of reliability-based robust design optimization (RBRDO) problems. In order to generate reliable and robust Pareto-optimal solutions, the combination of genetic algorithm with reliability assessment loop based on the performance measure approach is applied as 
the second stage. Next, we develop two criteria to select a solution from obtained Pareto optimal set to achieve the best possible implementation. Finally, the result verification is performed with Monte Carlo Simulations and also the quality improvement during manufacturing process is considered by identifying and controlling the critical variables.

Bruyneel [3] presented a general and effective procedure based on mathematical programming approach for the optimal design of composite structures subjected to weight, stiffness and strength criteria.

De Munck et al. [4], demonstrated how to minimize of both cost and mass by a multi-objective optimization. First, a two-objective size optimization procedure is developed, and subsequently its strength is illustrated on hybrid composite-concrete beams. An original methodology combining Nondominated Sorting Genetic Algorithm (NSGA-II) and a metamodel is used to find all optimal solutions.

An et al. [5], proposed a method to solve the problem of composite laminates assembled with other components, such as honeycomb or metal panels or stiffened beams. Together with stacking sequences, the cross-sectional dimensions of these components need to be considered simultaneously. A new optimization model is firstly established by involving both stacking sequence and sizing variables. Within a single procedure, the genetic algorithm is used to solve a first-level approximate problem which includes both types of variables, while a second-level approximate problem is addressed for the individual fitness calculations.

$\mathrm{Fu}$ et al. [6], modelized a strategy for multi-scale analysis and optimization of stiffened panels, made of three-dimensional woven composites. Artificial neural network techniques are utilized to generate an approximate response for the optimum structural design in order to increase efficiency and applicability. The artificial neural networks are integrated with genetic algorithms to optimize mixed discrete-continuous design variables for the three dimensional woven composite structures. The proposed procedure is then applied to the multi-objective optimal design of a stiffened panel subject to buckling and post-buckling requirements.

Le-Manh and Lee [7], presented an optimal procedure based on genetic algorithm and NURBS-based finite element isogeometric analysis (IGA) for seeking maximum load-carrying capacity of imperfect laminated composite plates with respect to a specified displacement. Nonlinear behavior of plates including bending, buckling and post buckling are investigated. Fiber orientations are the design variables.

Pelletier and Vel [8] have discussed the multi-objective design of symmetrically laminated plates for different criteria like strength, stiffness and minimal mass. Venkataraman and Haftka [9] presented a review of various approaches to the optimization of composite panels. Park et al. [10] used the genetic algorithm to optimize the laminated symmetrical composite using the finite element based on the shear deformation theory. Omkar et al. [11] used a method/generic model for the optimization of the multi-objective design (weight and cost), which is based on algorithm Vector Evaluated Artificial Bee Colony (VEABC). Yong et al. [12] used the genetic algorithm (GA) to optimize the response of composite laminate subjected to impact. Two different impact scenarios are presented: low and high velocity impact of a thin rectangular plate. In these cases, the aim of GA was to minimize the tip deflection and to minimize the penetration by varying the angles stacking respectively Aydin [13] studied the design of composite laminates subjected to hygrothermomechanical loading by mean of stochastic optimization.

Antoine and Batra [14], employed a genetic algorithm to maximize the energy dissipated per unit area in laminates composed of layers of poly-methyl-metha-acrylate (PMMA), adhesive and polycarbonate (PC) targeted at low velocity by a rigid hemi-spherical nosed cylinder. The results shown that the sources of energy dissipation considered are plastic deformations of the PC and the PMMA, cracking of the PMMA, viscous deformations of the adhesive, and the energy used to deform failed elements that are deleted from the analysis domain. Some of the results are appropriate constitutive relations for the three materials, failure criteria, and numerical techniques to accurately analyze finite deformations of different constituents. The commercial finite element software LS-DYNA in which these material models have been implemented as user defined subroutines was used.

Malik and Arif [15], used of Artificial Neural Networks to predict the absorbed energy in the composite laminate impacted with low velocity. The impact response of a composite laminate depends on various factors such as thickness, stacking sequence and number of layers. These factors are identified in an earlier study using the sensitivity analysis. These factors have the most effect on the impact behavior of the composite plates. These are studied here with the help of design of experiments (DOE) so that a suitable data set is obtained. The ability to solve a large number of simulations using FEA gives an advantage in the design optimization with the help of DOE (Design of Experiments). During the study different variations of these factors were tested and the response in terms of the absorbed energy was estimated. The simulation results were then used along with the ANN (Artificial Neural Networks) to fit a function to estimate the amount of absorbed energy.

Yong et al. [16], used a genetic algorithm (GA) to optimize the response of a composite laminate subject to impact. Two different impact scenarios are presented: low-velocity impact of a slender laminated strip and high-velocity impact of a rectangular plate by a spherical impactor. In these cases, the Genetic Algorithm objective function was used to, respectively, minimize the peak deflection and minimize penetration by varying the ply orientation. The GA was coupled to a commercial finite-element (FE) package LS DYNA to perform the impact analyses. 
Rahul et al. [17], deals with optimization of hybrid fiber reinforced plastic (FRP) laminated plates subjected to impact loading using island model parallel genetic algorithm (IMPGA). Finite element method (FEM) and IMPGA have been used to obtain optimum laminates in terms of minimizing the cost, weight or both cost and weight of Graphite/Epoxy (T300/5208)-Aramid/Epoxy (Kevlar 49) hybrid laminates. Impact induced delamination and matrix cracking have been used as failure criteria for the optimization of laminate. Fiber orientation, material and thickness in each lamina as well as number of lamina in the laminate have been used as design variables. Multi-objective approach has been used to achieve the optimum design of a laminate for combined normalized weighted cost and weight minimization. The results obtained from the integrated module show that IMPGA with FEM can lead to a global optimal solution for both single as well as multiple objective functions.

Alemi-Ardakani et al. [18], used a Taguchi design of experiments is a much known statistical method for cost/time reduction during experimental investigation and quality engineering of complex systems and processes. In the present article, efficiency, accuracy, strengths and limitations of this method in predicting and discretely optimizing impact response of FRP composites have been studied through a case study on polypropylene/E-glass laminates with unidirectional, plain, and twill weave architectures. In parallel, drop weight impact tests, $\mathrm{X}$-ray micro-tomography, and pre- and post-impact four-point flexural testing are employed for two purposes: (a) gaining further knowledge on induced impact damage mechanisms, and (b) further assessment and verification of the Taguchi results. In spite of the fact that impact events of the FRP laminates are highly nonlinear and accompany high level of uncertainty, it was found that this design of experiments method is capable of predicting and maximizing the absorbed impact energy.

Rahul et al. [19], deals with optimization of hybrid fiber reinforced plastic laminated plates subjected to impact loading. Finite element method (FEM) and genetic algorithm (GA) have been used to obtain optimum laminate in terms of minimizing the cost, weight or both cost and weight of graphite/epoxy (T300/5208)-aramid/epoxy (Kevlar 49) hybrid laminates while maximizing the strength. Impact induced delamination and matrix cracking have been used as failure criteria for the optimization of laminate. Fiber orientation, material and thickness in each lamina as well as number of lamina in the laminate have been used as design variables. Multi-objective approach has been used to achieve the optimum design of a laminate for combined normalized weighted cost and weight minimization. The results obtained from the integrated module show that genetic algorithm with finite element technique.

Khedmati et al. [20], optimization of stacking sequence for composite panels under slamming impact loads using a genetic algorithm method is studied in this paper. For this purpose, slamming load is assumed to have a uniform distribution with a triangular-pulse type of intensity function. In order to perform optimization based on a genetic algorithm, a special code is written in MATLAB software environment. The optimizer is coupled with the commercial software ANSYS in order to analyze the composite panel under study and calculate the central deflection. After validation, different cases of stacking sequence optimization are investigated for a variety of composite panels. The investigations include symmetric as well as asymmetric conditions of stacking sequence.

Yi et al. [21], used a coupling method for optimizing damage resistance of composite laminates under impact, a method of optimization based on solid-shell coupling finite element (FE) model was presented. Solid element was used to simulate the impact region, and shell element was used in the other region of the laminates in the model. They were connected by coupling constraint. A damage variable related to the number of fiber orientations was developed in the application of progressive damage material constitutive relationship. Optimization was implemented by genetic algorithm. Effectiveness of the damage resistance optimization method was demonstrated by classical examples. Ply stacking method of composite wingbox panel aiming at impact damage resistance was optimized. Results indicate that the method of genetic algorithm optimization based on solid-shell coupling model is highly efficient and well convergent.

\section{Failure criteria}

\subsection{Composite damage}

Weight, cost and structure minimization of composite structures necessarily involves strength constraints, because decreasing number of load carrying plies eventually leads to failure. The structure must be able to withstand the imposed loads without suffering any failure.

The Tsai-Wu failure criterion is one of the most reliable static failure criteria as it provides a simple analytical expression taking into account the competing interactive effects among the stress components [22].

$$
\begin{aligned}
& \frac{\sigma_{11}^{2}}{X_{t}\left|X_{c}\right|}+\frac{\sigma_{22}^{2}}{Y_{t}\left|Y_{c}\right|}-\frac{\tau_{12}^{2}}{S^{2}} \frac{\sigma_{11} \sigma_{12}}{\sqrt{X_{t} X_{c} Y_{t}}}-\left(\frac{1}{X_{t}}+\frac{1}{\left|X_{c}\right|}\right) \sigma_{11} \\
& +\left(\frac{1}{Y}+\frac{1}{\left|Y_{c}\right|}\right) \sigma_{22}<1 .
\end{aligned}
$$

The safety factor for the kth lamina, $\mathrm{SF}^{\mathrm{k}}$, according to the Tsai-Wu criterion is defined as the multiplier of the stress components at lamina $\mathrm{k}, \sigma_{\mathrm{ij}}^{\mathrm{k}}$, that makes the right hand side of Eq. (1) equal to 1.0, Eq. (1) then becomes:

$$
\left(S F^{k}\right)^{2}+b\left(S F^{k}\right)-1=0
$$

Where: 


$$
\begin{aligned}
& a=\frac{\sigma_{11}^{2}}{X_{t}\left|X_{c}\right|}+\frac{\sigma_{22}^{2}}{Y_{t}\left|Y_{c}\right|}-\frac{\tau_{12}^{2}}{S^{2}} \frac{\sigma_{11} \sigma_{12}}{\sqrt{X_{t} X_{c} Y_{t}}} \\
& b=\left(\frac{1}{X_{t}}-\frac{1}{\left|X_{c}\right|}\right) \sigma_{11}+\left(\frac{1}{Y}-\frac{1}{\left|Y_{c}\right|}\right) \sigma_{22} .
\end{aligned}
$$

The root of Eq. (2) gives the safety factor. Because a negative safety factor is not physically meaningful, the absolute value of the first root is considered as the actual safety factor.

$$
S F^{k}=\left|\frac{-b+\sqrt{b^{2}+4 a}}{2 a}\right| .
$$

Then, the minimum of $\mathrm{SF}^{\mathrm{k}}$ is chosen as the safety factor of the laminate.

\subsection{Delamination of composite}

Delamination failure occurs if the following is met:

$$
\left(\frac{\sigma_{3}}{Z_{t}}\right)^{2}+\left(\frac{\sigma_{5}}{S_{c b}}\right)^{2}+\left(\frac{\sigma_{6}}{S_{c a}}\right)^{2} \geq 1
$$

Where:

$\mathrm{S}_{\mathrm{ca}}$ Transverse shear strength.

$\mathrm{S}_{\mathrm{cb}}$ Transverse shear strength.

$\mathrm{Z}_{\mathrm{t}}$ Normal tensile strength c-axis.

So we have no delamination it is necessary that:

$$
\operatorname{Del}(x)=\left(\frac{\sigma_{3}}{Z_{t}}\right)^{2}+\left(\frac{\sigma_{5}}{S_{c b}}\right)^{2}+\left(\frac{\sigma_{6}}{S_{c a}}\right)^{2} .
$$

\section{Numerical modeling of impactors and laminate}

In this section, we consider graphite/epoxy laminate of stacking sequence $[0 / 30 / 45 / 60 / 90 / 45]_{\mathrm{s}}$. In Table 1, we present the mechanical properties of laminate and impactor. A circular notch of diameter $5 \mathrm{~mm}$ was drilled at a position shown in Fig. 1, then a laminate was targeted at the center by four different impactors made in stainless steel (ball, truncated cone, cylinder with hemispherical head, cylinder), all the laminate sides were clamped, Fig. 2. Among the lamina constitutive models available in LS-DYNA, the Mat Composite Failure Option Model $($ MAT059, Option $=$ Solid) [22], able to model the progressive damage of the material on the basis of a three-dimensional stress based failure criterion, was chosen in this work. Although the selection of MAT059 in shell formulation has been discussed in several applications available in literature [23], works or detailed descriptions investigating its behavior in 3D formulations are scarce and only few information. Solid elements are able to capture fully three-dimensional states of stress and are generally used to model thick parts or continua. In contrast, parts that are relatively thin in one direction are generally modeled with shell elements. To model a thin part with solids can be expensive since the smallest dimension of a solid will control its time step, and generally two or more solid elements through the thickness are required to produce an accurate response. For solid elements, the corresponding element formulations exist with more options if shear locking is for example present. If eight-noded brick elements are to be used, the recommended element formulations are either the default formulation with one integration point, denoted as "ELFORM $=1$ " or the fully integrated solid formulation, denoted as "ELFORM = 2" which provides eight integration points on the element surface. The biggest disadvantage to one-point integration is the need to control the zero energy modes, which arise, called hourglassing modes. Undesirable hourglass modes tend to have periods that are typically much shorter than the periods of the structural response, and they are often observed to be oscillatory. However, hourglass modes that have periods that are comparable to the structural response periods may be a stable kinematic component of the global deformation modes and must be admissible. One way of resisting undesirable hourglassing is with a viscous damping or small elastic stiffness capable of stopping the formation of the anomalous modes but having a negligible effect on the stable global modes. Ply element deleting criterion was added by using ADDEROSION card, which allows elements to be deleted from the calculation.

Table 1 Mechanical property of laminate and impactor [24]

\begin{tabular}{ccccccc}
\hline $\begin{array}{c}\mathrm{E}_{11} \\
\mathrm{GPa}\end{array}$ & $\begin{array}{c}\mathrm{E}_{22} \\
\mathrm{GPa}\end{array}$ & $\begin{array}{c}\mathrm{E}_{33} \\
\mathrm{GPa}\end{array}$ & $v_{12}$ & $v_{23}$ & $v_{13}$ & $\begin{array}{c}\mathrm{G}_{12} \\
\mathrm{GPa}\end{array}$ \\
\hline 122 & 8 & 8 & 0.1 & 0.2 & 0.2 & 4.5 \\
$\mathrm{Xt}$ & $\mathrm{Xc}$ & $\mathrm{Yt}$ & $\mathrm{Yc}$ & $\mathrm{Zt}$ & $\mathrm{Zc}$ & $\mathrm{S}_{12}$ \\
$\mathrm{GPa}$ & $\mathrm{GPa}$ & $\mathrm{GPa}$ & $\mathrm{GPa}$ & $\mathrm{GPa}$ & $\mathrm{GPa}$ & $\mathrm{GPa}$ \\
1.835 & 0.7 & 0.040 & 0.184 & 0.08 & 2.5 & 0.0415 \\
$\mathrm{G}_{23}$ & $\mathrm{G}_{13}$ & $\mathrm{~S}_{23}$ & $\mathrm{~S}_{13}$ & $\rho$ & & \\
$\mathrm{GPa}$ & $\mathrm{GPa}$ & $\mathrm{GPa}$ & $\mathrm{GPa}$ & $\mathrm{kg} / \mathrm{m}^{3}$ & & \\
1.5 & 1.5 & 0.055 & 0.055 & 1497 & & \\
& & $\rho$ & & & & \\
Impactor & $\mathrm{E}(\mathrm{GPa})$ & $\mathrm{kg} / \mathrm{m}^{3}$ & $v$ & & & \\
& 207 & 7850 & 0.3 & & & \\
\hline
\end{tabular}

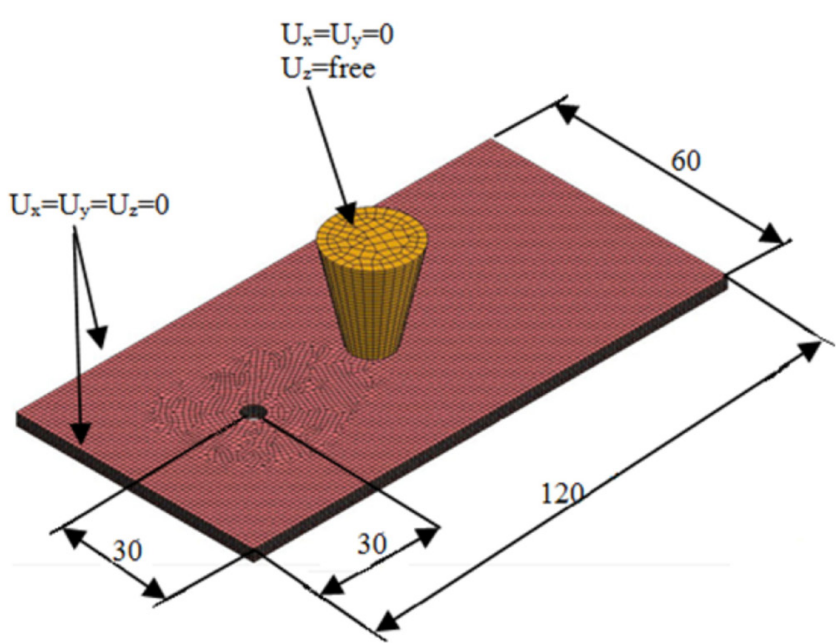

Fig. 1 Boundary conditions of drilled laminate plate impacted by truncated cone 


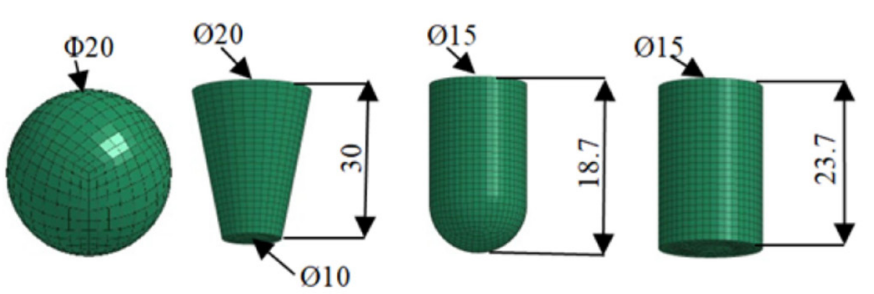

Fig. 2 Geometry of impactors

Solid elements are able to capture fully three-dimensional states of stress and are generally used to model thick parts or continua. In contrast, parts that are relatively thin in one direction are generally modeled with shell elements. The biggest disadvantage to one-point integration is the need to control the zero energy modes, which arise, called hourglassing modes. Undesirable hourglass modes tend to have periods that are typically much shorter than the periods of the structural response, and they are often observed to be oscillatory. The values of IHQ (Hourglassing viscosity type $)=4$ and $\mathrm{QH}($ Hourglassing coefficient $)=0.1$.

The laminate has been modeled by using the solid element formulation. The total number of solid elements used was 21576, while the number of solid element nodes was about 44365 and the end time simulation was $4 \mathrm{~ms}$. Each element has eight nodes with three degrees of freedom at each node and one integration point, through the laminate thickness. The automatic_surface to_surface has been used to model the contact between the impactor and the laminate and the contact_automatic_surface_to_surface_tiebreak between the layers.

All the impactors target laminate at center. The truncated cone, cylinder dropped by little surfaces.

\section{Genetic algorithm}

Genetic searches the minimum or the extreme of a function defined on a data space. To use, we must have the following five elements [25]:

- A coding principle of population element.

- A generating mechanism of the initial population.

- A function to be optimized.

- Operators to diversify the population over generations and explore the state space. (The crossover operator, the mutation operator).

- Design parameters: the size of the population, total number of generations or stopping criterion. Application of probability of crossover and mutation operators.

The genetic algorithm requires a large number of iterations compared gradient based algorithm. The steps in a simple genetic algorithm [26] are illustrated on Fig. 3.

\subsection{Formulation of the objective function}

The objective function is usually formulated according to the optimization problem. In the present study, the safety factor

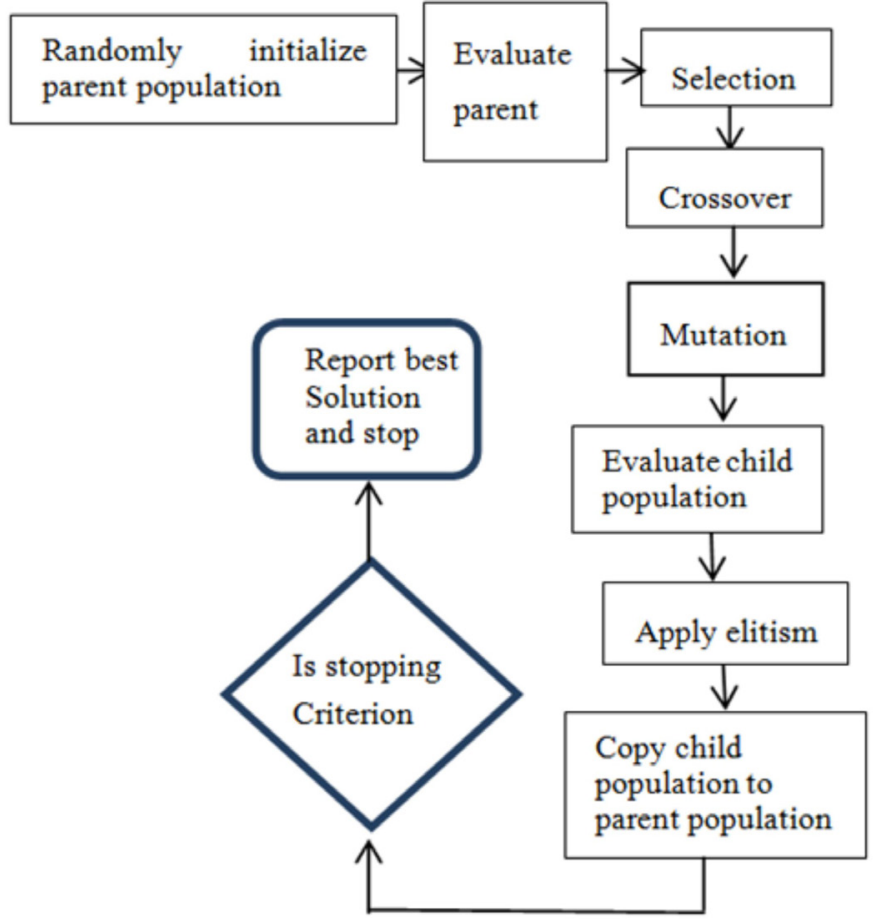

Fig. 3 Simple genetic algorithm

is used as objective function; it is derived from the Tsai-Wu criterion, Eq. (1). This optimization for maximum energy seeks for a minimum safety factor, energy as variable $(\mathrm{v}=$ variable $)$. For this we had the optimization settings as follows:

The optimized function is:

$$
F(x)=\min \left(S F^{k}\right) .
$$

In Table 2, we present the constrained variables used in optimization process, like velocity (continued variable) and the elastic Young modulus in two directions and the layer orientations. In the second optimization, we include the delamination criteria, Eq. (4) as objective function.

\begin{tabular}{lcc}
\multicolumn{3}{c}{ Table 2 Constrained values } \\
\hline Lower bound & Upper bound \\
\hline Safety coef. & 1.5 & 3 \\
Velocity & 5 & 25 \\
$\mathrm{E}_{11}(\mathrm{GPa})$ & 134 & 524 \\
$\mathrm{E}_{22}(\mathrm{GPa})$ & 5.7 & 7 \\
Layer angles & $0-30-45-60-90$ & \\
Delamination function & 0 & 1 \\
\hline
\end{tabular}

The package Ls-optui [26] was used for optimization. This software was linked to Ls-Dyna code. During the optimization process, we used the data listed below:

Population $=10$

Generation $=60$

Crossover: sbx

Prob_crossover $=1$

Prob_mutation $=0.16$ 
Table 3 Optimized values of Young modulus, safety factor and optimal layup

\begin{tabular}{|c|c|c|c|c|c|c|}
\hline Truncated cone & 134 & 6.967 & 0.01820 & 1.076 & 5.807 & $(0 / 90 / 0 / 0 / 90 / 90)_{\mathrm{s}}$ \\
\hline Ball & 134 & 6.961 & 0.01818 & 1.064 & 5 & $(0 / 90 / 0 / 0 / 90 / 90)_{\mathrm{s}}$ \\
\hline Hemispherical & 134 & 6.687 & 0.01746 & 1.079 & 5 & $(0 / 90 / 0 / 0 / 90 / 90)_{\mathrm{s}}$ \\
\hline \multirow[t]{2}{*}{ Cylinder } & 138.41 & 6.031 & 0.0178 & 1.004 & 11.357 & $(60 / 60 / 30 / 30 / 0 / 45)$ \\
\hline & $\mathrm{E}_{11}(\mathrm{GPa})$ & $\mathrm{E}_{22}(\mathrm{GPa})$ & $v_{12}$ (Poisson ratio) & S.F. & Velocity $(\mathrm{m} / \mathrm{s})$ & Layup \\
\hline
\end{tabular}

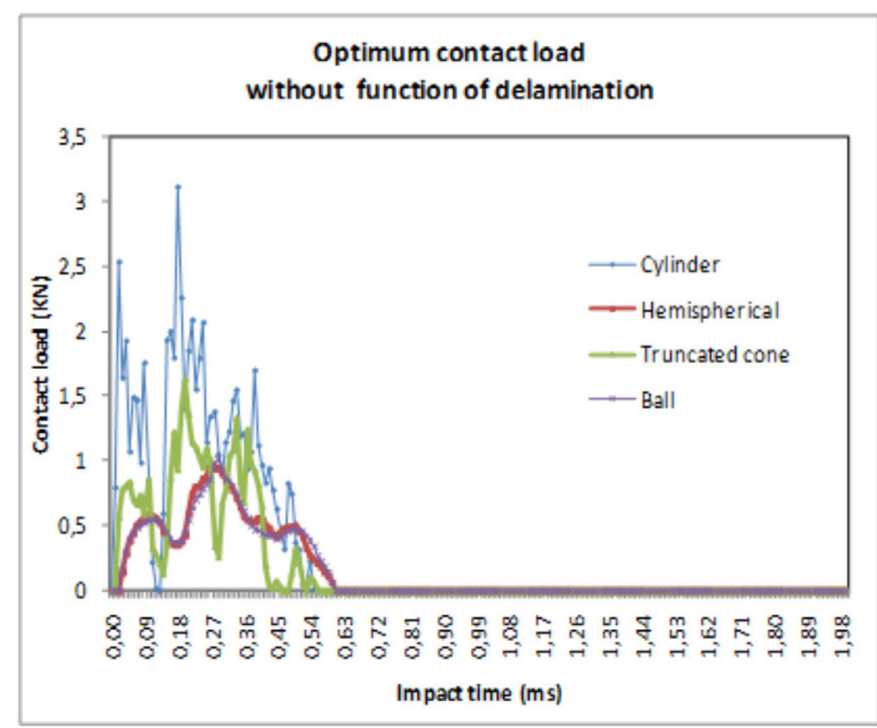

Fig. 4 Optimized contact load

\section{Results and discussion}

\subsection{Without function of delamination}

In Table 3, the optimization results are presented. We note that the all the impactors shown more or less the same the same safety factor about 1.013. The cylinder present a high value of young modulus $\mathrm{E}_{11}$ about of $138 \mathrm{GPa}$, while the young modulus $\mathrm{E}_{22}$ take a lower value (6.031 GPa).

The Fig. 4, illustrate the optimized contact load versus impact time without taking account the function of delamination. The cylinder impactor provides a maximum contact load about of $3.1 \mathrm{KN}$; the truncated cone impactor gives the contact load about of $1.62 \mathrm{KN}$. The hemispherical and the ball impactors provide more or less the same value about of $1.02 \mathrm{KN}$. From Fig. 5, the displacement provided by the cylinder was $1.56 \mathrm{~mm}$; the truncated cone gives a value about of $0.74 \mathrm{~mm}$. The hemispherical and the ball generate a displacement about of $0.82 \mathrm{~mm}$.

In Fig. 6, we illustrate the maximal interlayer's delamination area. We note that the ball impactor provide a minimal value about of $0.83 \mathrm{~mm}^{2}$ at interface (60/90). Hence, the cylinder generated at the interface (90/45) maximal delamination area about of $4.78 \mathrm{~mm}^{2}$.

\subsection{With function of delamination}

In this section we take account the function of delamination, Eq. (4) with the safety coefficient as objective function. In Fig. 7, the maximal contact load was $1.63 \mathrm{KN}$ generated by a truncated cone, followed by a cylinder about of $1.40 \mathrm{KN}$.

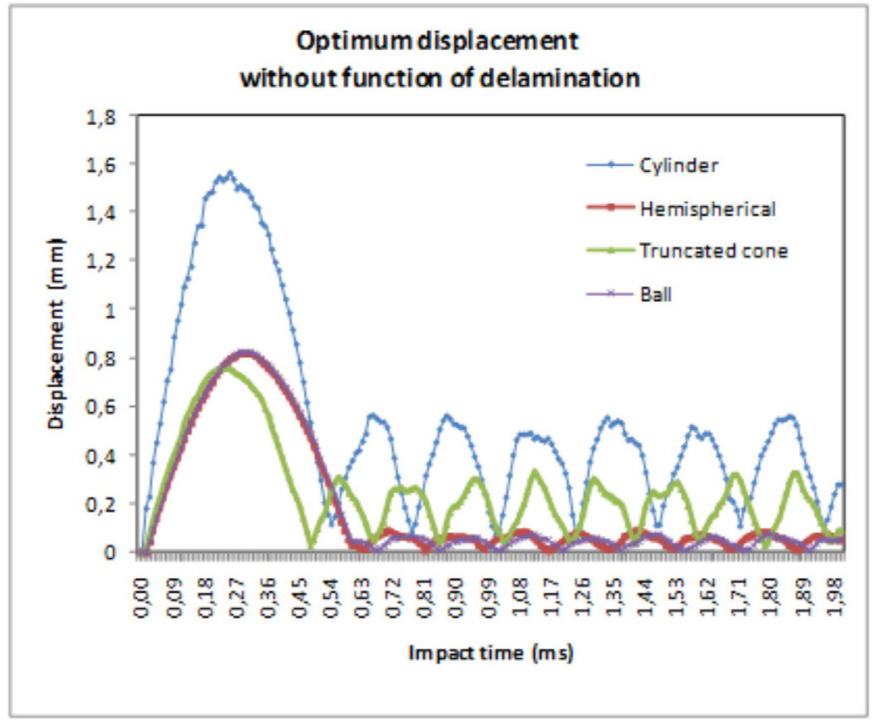

Fig. 5 Optimized displacement

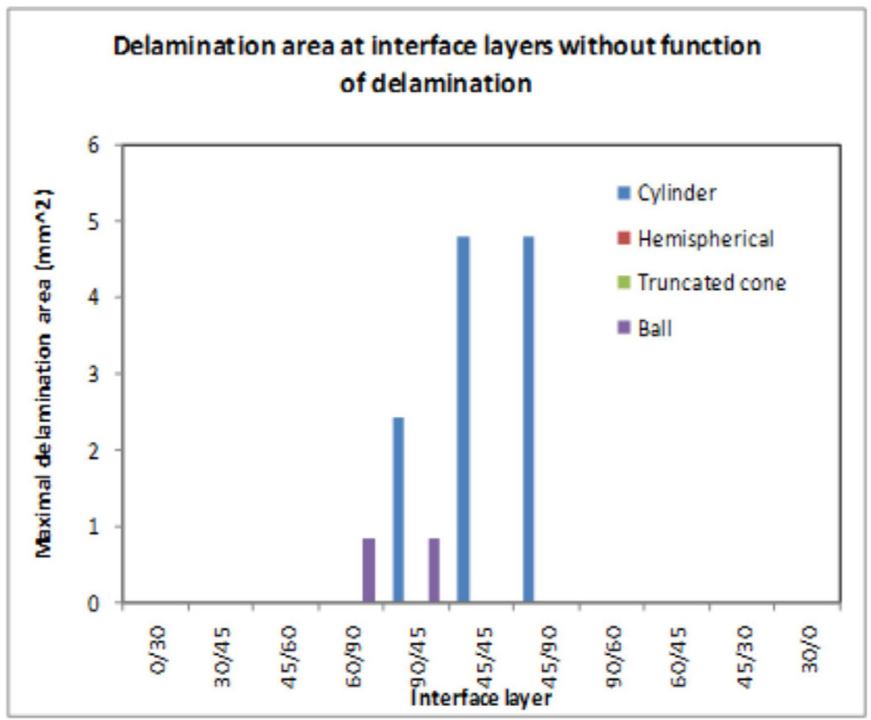

Fig. 6 Optimized delamination area

The minimal values were given by a hemispherical and the ball impactors. From Fig. 8, the cylinder gives a lower value of displacement about of $0.60 \mathrm{~mm}$; the hemispherical and the ball provides more or less the same value about of $0.845 \mathrm{~mm}$.

In Fig. 9, we present the effective stresses. The hemispherical impactor generated a maximal stresses about of $0.63 \mathrm{GPa}$, followed by a ball about of $0.52 \mathrm{GPa}$. The lowest stress value was given by a cylinder about of $0.24 \mathrm{GPa}$.

From Table 4, we note that the function of delamination in the case of ball and hemispherical impactors was greatening to unit, hence the delamination take place. 
Table 4 Optimized values of Young modulus, safety factor and optimal layup with delamination function

\begin{tabular}{|c|c|c|c|c|c|c|c|}
\hline Truncated cone & 134 & 6.962 & 0.01818 & 1.137 & 5.807 & $(0 / 90 / 0 / 0 / 90 / 90)_{\mathrm{s}}$ & 0.836 \\
\hline Ball & 134 & 6.961 & 0.01818 & 1.188 & 5.269 & $(90 / 90 / 0 / 45 / 90 / 90)_{\mathrm{s}}$ & 2.11 \\
\hline Hemispherical & 140.873 & 6.234 & 0.0154 & 1.425 & 5.193 & $(45 / 90 / 0 / 45 / 90 / 90)_{\mathrm{s}}$ & 2.04 \\
\hline \multirow[t]{2}{*}{ Cylinder } & 134 & 6.961 & 0.01818 & 1.532 & 11.357 & $(0 / 90 / 0 / 0 / 90 / 90)_{\mathrm{s}}$ & 0.514 \\
\hline & $\mathrm{E}_{11}(\mathrm{GPa})$ & $\mathrm{E}_{22}(\mathrm{GPa})$ & $v$ (Poisson ratio) & S.F. & Velocity $(\mathrm{m} / \mathrm{s})$ & Layup & Delamination function \\
\hline
\end{tabular}

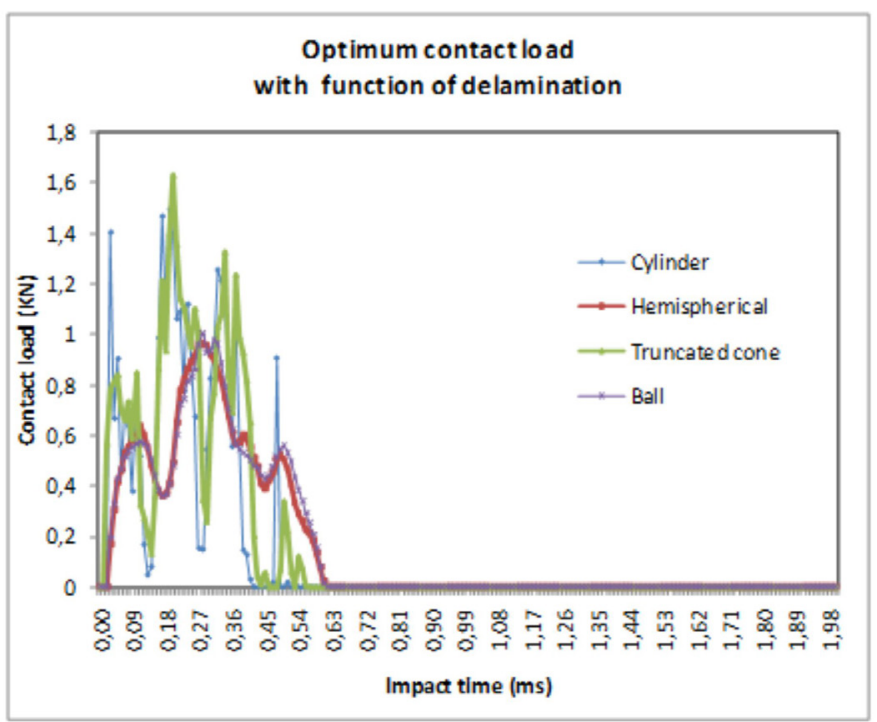

Fig. 7 Optimized contact load

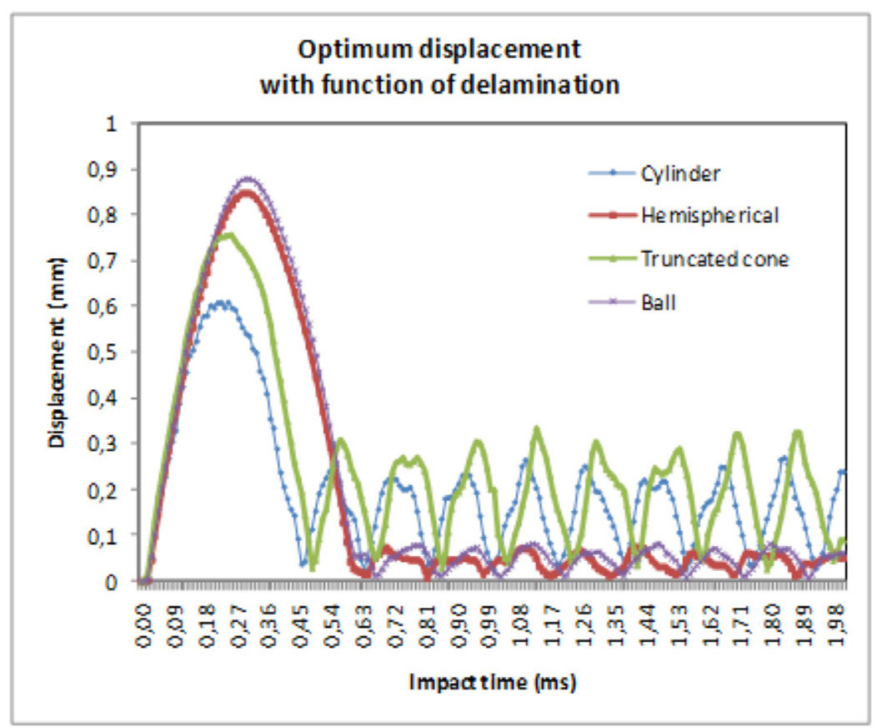

Fig. 8 Optimized displacement

\section{Conclusion}

The objective of the present paper was the optimization of the safety factor derived from the Tsai-Wu criterion by mean of the genetic algorithm for optimal design. The optimization process was carried out on a carbon/epoxy composite of stacking sequence $[0 / 30 / 45 / 60 / 90 / 45]_{\mathrm{s}}$ with circular notch. The Mat059 and Mat020 Lsdyna finite element models were used to model the laminate and the impactor. The optimization was held by taking the velocity, Young modulus and the layer orientations as variables. The safety coefficient and the delamination function

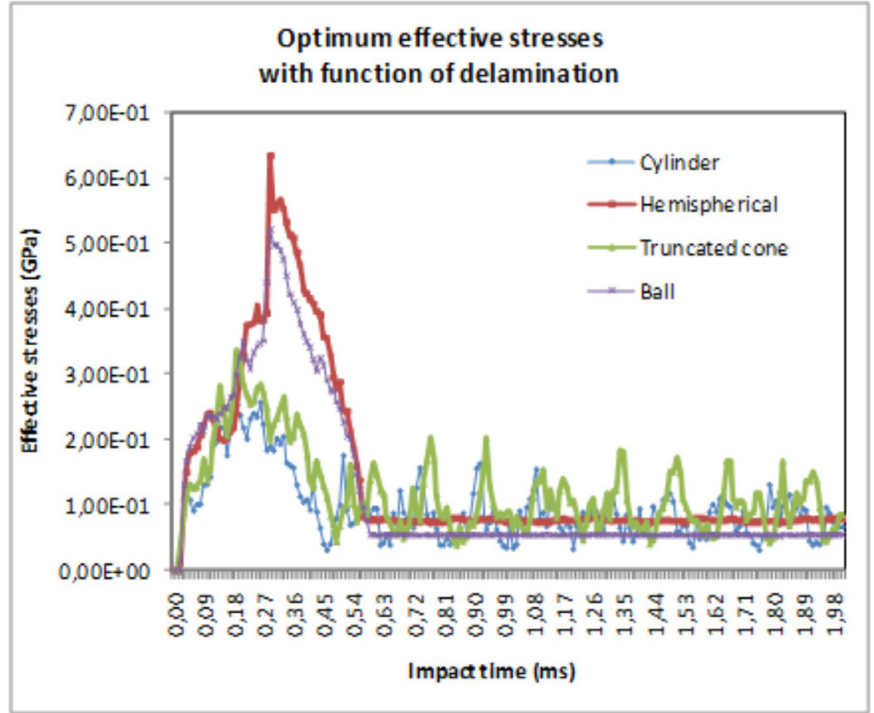

Fig. 9 Optimized effective stresses

are taken as multi-objective function. Without the function of delamination the safety factor was a more or less superior to unit. In the second case with the function of delamination, the safety factor was between 1.13 and 1.53 . The optimal sequences are $(0 / 90 / 0 / 0 / 90 / 90)_{\mathrm{s}},(90 / 90 / 0 / 45 / 90 / 90)_{\mathrm{s}},(45 / 90 / 0 / 45 / 90 / 90)_{\mathrm{s}}$, $(0 / 90 / 0 / 0 / 90 / 90)_{s}$. The circular notch had an effect on the stress field that affect the behaviour of the laminate.

\section{References}

[1] de Almeida, F. S. "Stacking sequence optimization for maximum buckling load of composite plates using harmony search algorithm." Composite Structures. 143, pp. 287-299. 2016.

https://doi.org/10.1016/j.compstruct.2016.02.034

[2] Shahraki, A. F., Noorossana, R. "Reliability-based robust design optimization: A general methodology using genetic algorithm." Computers \& Industrial Engineering. 74, pp. 199-207. 2014.

https://doi.org/10.1016/j.cie.2014.05.013

[3] Bruyneel, M. "A general and effective approach for the optimal design of fiber reinforced composite structures." Composites Science and Technology. 66(10), pp. 1303-1314. 2006.

https://doi.org/10.1016/j.compscitech.2005.10.011

[4] De Munck, M., De Sutter, S., Verbruggen, S., Tysmans, T., Coelho, R. F. "Multi-objective weight and cost optimization of hybrid composite-concrete beams." Composite Structures. 134, pp. 369-377. 2015. https://doi.org/10.1016/j.compstruct.2015.08.089

[5] An, H., Chen, S., Huang, H. "Simultaneous optimization of stacking sequences and sizing with two-level approximations and a genetic algorithm." Composite Structures. 123, pp. 180-189. 2015.

https://doi.org/10.1016/j.compstruct.2014.12.041 
[6] Fu, X., Ricci, S., Bisagni, C. "Minimum-weight design for three dimensional woven composite stiffened panels using neural networks and genetic algorithms." Composite Structures. 134, pp. 708-715. 2015. https://doi.org/10.1016/j.compstruct.2015.08.077

[7] Le-Manh, T., Lee, J. "Stacking sequence optimization for maximum strengths of laminated composite plates using genetic algorithm and isogeometric analysis." Composite Structures. 116, pp. 357-363. 2014. https://doi.org/10.1016/j.compstruct.2014.05.011

[8] Pelletier, J. L., Vel, S. S. "Multi-objective optimization of fiber reinforced composite laminates for strength, stiffness and minimal mass." Computers and Structures. 84(29-30), pp. 2065-2080. 2006. https://doi.org/10.1016/j.compstruc.2006.06.001

[9] Venkataraman, S., Haftka, R. T. "Optimization of composite panels - A review." In: Proceedings of the 14th Annual Technical Conference of the American Society of Composites, Dayton, Ohio, USA, Sept. 27-29, 1999. pp. 479-488. [Online]. Available from: https://www.researchgate.net/ publication/235973313_Optimization_of_composite_panels-_A_review [Accessed: 1st October 2017]

[10] Park, J. H., Hwang, J. H., Lee, C. S., Hwang, W. "Stacking sequence design of composite laminates for maximum strength using genetic algorithms." Composite Structures. 52(2), pp. 217-231. 2001. https://doi.org/10.1016/S0263-8223(00)00170-7

[11] Omkar, S. N., Senthilnath, J., Khandelwal, R., Narayana Naik, G., Gopalakrishnan, S. "Artificial Bee Colony (ABC) for multi-objective design optimization of composite structures." Applied Soft Computing. 11(1), pp. 489-499. 2011. https://doi.org/10.1016/j.asoc.2009.12.008

[12] Yong, M., Falzon, B. G., Iannucci, L. "On the application of genetic algorithms for optimizing composites against impact loading." International Journal of Impact Engineering. 35(11), pp. 1293-1302. 2008. https://doi.org/10.1016/j.ijimpeng.2007.10.004

[13] Aydin, L. "Design of dimensionally-stable laminated composites subjected to hygro-thermo-mechanical loading by stochastic optimization methods." PhD Thesis, Izmir Institute of Technology, Ismir, Turkey, 2011. [Online]. Available from: http://library.iyte.edu.tr/tezler/doktora/ makinamuh/T000984.pdf [Accessed: 1st October 2017]

[14] Antoine, G. O., Batra, R. C. "Optimization of transparent laminates for specific energy dissipation under low velocity impact using genetic algorithm." Composite Structures. 124, pp. 29-34. 2015. https://doi.org/10.1016/j.compstruct.2014.12.066

[15] Malik, M. H., Arif, A. F. M. "ANN prediction model for composite plates against low velocity impact loads using finite element analysis." Composite Structures. 101, pp. 290-300. 2013. https://doi.org/10.1016/j.compstruct.2013.02.020

[16] Yong, M., Falzon, B. G., Iannucci, L. "On the application of genetic algorithms for optimizing composites against impact loading." International Journal of Impact Engineering. 35(11), pp. 1293-1302. 2008. https://doi.org/10.1016/j.ijimpeng.2007.10.004
[17] Rahul, Chakraborty, D., Dutta, A. "Optimization of FRP composites against impact induced failure using island model parallel genetic algorithm." Composites Science and Technology. 65(13), pp. 2003-2013. 2005. https://doi.org/10.1016/j.compscitech.2005.03.016

[18] Alemi-Ardakani, M., Milani, A. S., Yannacopoulos, S., Borazghi, H. "A rapid approach for predication and discrete lay-up optimization of glass fiber/polypropylene composite laminates under impact." International Journal of Impact Engineering. 84, pp. 134-144. 2015.

https://doi.org/10.1016/j.ijimpeng.2015.05.012

[19] Rahul, Sandeep, G., Chakraborty, D., Dutta, A. "Multi-objective optimization of hybrid laminates subjected to transverse impact." Composite Structures. 73(3), pp. 360-369. 2006.

https://doi.org/10.1016/j.compstruct.2005.02.008

[20] Khedmati, M. R., Sangtabi, M. R., Fakoori, M. "Stacking sequence optimization of composite panels subjected to slamming impact loads using a genetic algorithm." Latin American Journal of Solids and Structures. 10(5), pp. 1043-1060. 2013. https://doi.org/10.1590/S1679-78252013000500010

[21] Yi, P., Li, Z., Chen, X., Yu, Z., Wang, H. "Optimizing damage resistance of composite under low-velocity impact based on the application of solid-shell coupling model." Acta Materiae Compositae Sinica. 30(3), pp. 191-197. 2013. [Online]. Available from: http://fhclxb.buaa.edu.cn/ EN/abstract/article_11912.shtml [Accessed: 3rd September 2017]

[22] DeTeresa, S. J., Larsen, G. J. "Derived Interaction Parameters for the Tsai-Wu Tensor Polynomial Theory of Strength for Composite Materials". In: 2001 American Society of Mechanical Engineers International Mechanical Engineering Congress \& Exposition, New York, USA, Nov. 11-16, 2001. [Online]. Available from: https://www.osti.gov/scitech/biblio/15004792 [Accessed: 15th September 2017]

[23] LS-DYNA Keyword User's Manual, Multi-Physics Solvers. Livermore Software Technology Corporation. Livermore, California, USA. Vol. 3, 2017. [Online]. Available from: http://ftp.lstc.com/anonymous/outgoing/ jday/manuals/DRAFT_Vol_III.pdf [Accessed: 15th September 2017]

[24] Ilyas, M. "Damage modeling of carbon epoxy laminated composites submitted to impact loading." $\mathrm{PhD}$ Thesis, Institut Supérieur de l'Espace, Toulouse, France, 2010. [Online]. Available from: http://oatao.univ-toulouse.fr/4272/1/Espinosa_4272.pdf [Accessed: 25th September 2017]

[25] Sivanandam, S. N., Deepa, S. N. "Introduction to Genetic Algorithm." Springer Edition, Berlin, Heidelberg, Germany. 2008. https://doi.org/10.1007/978-3-540-73190-0

[26] LS-OPT User's Manual, "A Design Optimization and Probabilistic Analysis Tool for the Engineering Analyst." Version 5.2, Livermore Software Technology Corporation. Livermore, California, USA. 2015. [Online]. Available from: https://www.lsoptsupport.com/documents/manuals/lsopt/1s-opt-5.2-manual/view [Accessed: 25th November 2017] 